\title{
A social network perspective on the interaction between policy bubbles
}

Moshe Maor

\section{(2) OpenEdition \\ Journals}

Electronic version

URL: http://journals.openedition.org/irpp/774

DOI: $10.4000 /$ irpp. 774

ISSN: 2706-6274

Publisher

International Public Policy Association

\section{Printed version}

Date of publication: 27 April 2020

Number of pages: $24-44$

ISSN: 2679-3873

\section{Electronic reference}

Moshe Maor, "A social network perspective on the interaction between policy bubbles », International Review of Public Policy [Online], 2:1 | 2020, Online since 01 April 2020, connection on 11 June 2020. URL : http://journals.openedition.org/irpp/774 ; DOI : https://doi.org/10.4000/irpp.774

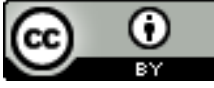




\section{A social network perspective on the interaction between policy bubbles}

\section{Moshe Maor}

Department of Political Science, The Hebrew University of Jerusalem, Israel

\section{Abstract}

Studies of policy bubbles have so far ignored the possibility that a policy bubble in a given policy domain or jurisdiction may constitute an information event for another policy bubble that has been inflated elsewhere. In addition, studies of policy diffusion have paid little attention to the transmission of imperfect and wrongful policy valuations through social networks. To bridge these gaps, this article develops a theoretical framework and methodological toolbox for explaining the potential impact of interbubble dynamics on the sustainment of policy bubbles. This is achieved by focusing on: (i) the diffusion of interbubble connectivity information through social networks characterized by varying levels of segregation; (ii) the perceptions of distorted or corrected information by individuals at the receiving end as being factual, thus requiring no gap-filling by policy actors, or as an opinion that therefore requires gap-filling; (iii) the derived consequence in terms of simple or complex contagion; and (iv) its impact on the sustainment of policy bubbles. The main contribution of the article lies in unpacking the potential causal mechanisms through which a policy bubble can be sustained, even if positive feedback processes and contagion in the jurisdiction within which it developed no longer bolster its support bases.

\section{Keywords}

interbubble dynamics, connectivity information, social networks, network segregation 
In recent years there has been growing interest in the efficiency of policymakers in matching the intensity of policy tools to the intensity of problems in the long term. In this regard, one of the most intriguing complex public-policy phenomena is that of policy bubbles. Jones et al. (2014), as well as Maor (2014), defined and conceptualized this phenomenon as a policy overinvestment or overreaction that is sustained by positive feedback processes and contagion over a relatively long time period. Furthermore, preliminary findings, based on "likely examples" of policy bubbles, have revealed that US crime policy, as well as contracting and privatization, constituted bubbles (Jones et al. 2014). Moving beyond this basic finding has proved difficult and, in fact, no empirical study to date has systematically identified and examined policy bubbles, or developed a reliable and useful methodology for measuring these phenomena. These lacunae notwithstanding, this conceptual article unpacks the potential causal mechanisms through which a policy bubble can be sustained - even if self-reinforcing processes and contagion in the jurisdiction wherein it developed no longer bolster its support base - in order to guide scholars who seek to address the aforementioned empirical gaps.

Studies of policy bubbles have so far analyzed standalone bubbles by focusing mainly on the policy domain as the unit of analysis. Little attention has been devoted to the connective tissue that may exist between policy bubbles, namely the shared information set that potentially links one policy bubble to another. Drawing on this idea, the present article develops a theoretical framework and methodological toolbox for the study of interbubble dynamics. The analytical framework focuses on: the diffusion of interbubble connectivity information through social networks characterized by varying levels of segregation; the perceptions of distorted or corrected information by individuals at the receiving end as being factual, thus requiring no gap-filling by policy actors, or as an opinion that therefore require gap-filling; the derived consequence in terms of simple or complex contagion; and its impact on policy bubble sustainment.

The article is structured as follows. The next section introduces a motivational example; the second reviews existing scholarly literature on policy bubbles; and the third describes the analytical premises, components and considerations underlying the study of interbubble dynamics. The sections thereafter outline the theoretical framework and the derived hypotheses. The methodological section subsequently proposes three research strategies. The last section suggests avenues for future research.

\section{Motivational Example}

A salient example of a shared information set linking one policy bubble to another is the culture of fear - exacerbated by media coverage adopting the immigration threat narrative - that was highly evident during the 1990s and 2000s as the US experienced a period of heightened activity in three policy domains. First, were the domains of crime and punishment - leading to a policy bubble (Jones et al. 2014). Second, was the domain of immigration - leading to record deportations during the Obama administration and an unprecedented rise in anti-immigrant legislation at state level in the period between 2005 and 2012 (e.g., Ybarra et al. 2016). And third, there was the policy domain of education within those states with large and swiftly growing Latino populations (i.e., those with the greatest need for public spending) - leading to a negative policy bubble that manifested in a long-term propensity to disinvest in this policy area (Abrajano and Hajnal 2015).

The culture of fear of immigrants provided a foundation upon which threat narratives - stories, songs, jokes, theories and explanations that have "emotional resonance and that can eas- 
ily be conveyed in casual conversation" (Shiller 2019, xi) — were formulated by policy actors and transmitted from one domain to another. These false narratives solidified (Andreas 2000; Abrajano and Hajnal 2015; Chavez 2008; Martinez-Brawley and Zorita 2018; Massey and Pren 2012), enhancing the misalignment between public perceptions about the policy problem, on the one hand, and data regarding the severity of the problem, on the other. The culture of fear may have also lowered the forgetting rate (Shiller 2019) of these narratives.

The analytical value of modeling this process becomes more pronounced when considering the transmission of housing bubbles through the credit market to other economic sectors. Based on data from the massive boom-bust cycle in Spanish housing prices between 1995 and 2015, Martín, Moral-Benito and Schmitz (2019) found that "housing bubbles initially crowd out credit from other sectors, but eventually — if they last long enough — crowd it in [by providing collateral or attractive assets for securitization]." The culture of fear in the aforementioned example may have operated as a symbolic and ideational credit market. It easily enabled policy actors to build up false policy narratives that resonated emotionally and these, in turn, crowded out correct policy valuations because they were more contagious. Furthermore, these narratives may have continued to affect policy investment long after they were corrected because they were more contagious. The culture of fear, therefore, may have linked different policy domains, refocusing individuals' attention and policy investment decisions on policy problems whose value could easily be distorted by triggering threat narratives. Traditional policy bubble theories do not offer a model for this process.

\section{Policy Bubbles: Relevant Literature}

A critical aspect of policy development over time is policymakers' inability to respond proportionally to information that indicates a change in a problem's severity. As leverage, the concept of policy bubbles has entered the policy lexicon (Jones et al. 2014; Maor 2014) and has been defined in terms of sustained policy overinvestment, which occurs when a government invests in a single policy instrument beyond its instrumental value in achieving a policy goal (adapted from Jones et al. 2014, 149), or sustained policy overreaction, which is a policy that "impose[s] objective and/or perceived social costs without producing offsetting objective and/or perceived benefits" (Maor 2012, 235).

To facilitate the distinction between the phenomenon and its explanation, Maor $(2019,14)$ recently defined the term as "a socio-psychological phenomenon which occurs when policy overinvestment or overproduction due to distorted policy valuation is sustained by positive feedback processes and contagion over an extended period of time." Distortion of policy valuation occurs when political and/or policy interests shape the presentation of policy-relevant scientific facts, which are based on objective measures, to fit distinct models of "reality" (Jasanoff 1987, 195; Nisbet and Mooney 2007; Oreskes and Conway 2010; Pielke 2007), thereby undermining an accurate assessment of the risks and benefits associated with the policy instrument at hand. Recently, the notion of policy bubbles was conceptually extended by focusing on the role of emotions in processes of sustained policy underreaction, termed negative policy bubbles (Maor 2016).

Studies of policy bubbles have so far analyzed standalone bubbles by focusing mainly on the policy domain as the unit of analysis (Jones et al. 2014; Maor 2014; Baumgartner 2015; Behn et al. 2015; Gillard and Lock 2017). Little attention has been devoted, however, to the potential connective tissue between policy bubbles, namely the shared (factual and/or symbolic/ ideational) information set that potentially links one policy bubble to another. This may have 
occurred because the concept of a policy bubble is itself relatively new, or because this phenomenon appears to be an instance of path dependencies and policy legacies interfering with policymakers' efficiency in reflecting genuine supply and demand for policies. Jones et al. (2014) went even further, omitting the symbolic and ideational components in the definition of a policy's instrumental value, although recognizing that "[p]olicies may come to be valued (or devalued) for reasons that may have little to do with the ability of the policy to affect goals, because much of politics is conducted at the symbolic or ideological level" (Jones et al. 2014, 149). This omission, in turn, has directed the radar away from the potential influences that one bubble may have on another. Once one recognizes that policy bubbles may share an information set, a new causal mechanism for the sustainment of policy bubbles emerges.

Yet, before conceptually uncovering this potential causal mechanism, an important question is in order: Given the expansive literature on policy diffusion - defined as the "process through which political [or policy] phenomena spread from one jurisdiction to another" (Karch et al. 2016 , 83), why do we need a theoretical framework dealing particularly with diffusion in relation to policy bubbles? This is necessary because diffusion explanations in policy sciences focus on: (i) governments' adoption of new policies (Berry and Berry 2018, 254) rather than the sustainment of new or old policy bubbles; (ii) intergovernmental dynamics rather than socio-psychological processes at the societal and elite levels; (iii) accurate policy information or perceptions thereof (Shipan and Volden 2008; Gilardi 2010; Seljan and Weller 2011), rather than distorted policy valuations that shape policy perceptions; and (iv) the spread of information rather than the spread of behaviors (Centola 2018), which may be highly important when an ends-means relationship between the intensity of the policy problem and the intensity of the policy instrument is replaced by a self-sustaining process. Current diffusion studies tell us little about: the kinds of social networks that are best suited to spreading imperfect or wrong information regarding a policy; the specific features of the network structure that affect the diffusion of distorted information, which cannot easily be corrected; and the diffusion of behavior, which does not follow the disease theory of diffusion (Centola 2018).

\section{Interbubble Dynamics: Analytical Premises, Components and Considerations}

Underlying this conceptual article is the premise that, by abstracting from a policy system in order to explain a standalone policy bubble, we risk severely misunderstanding the full spectrum of factors that may determine the sustainment of policy bubbles. To counteract this tendency, we require a deep understanding of: (i) how policy-relevant information and behaviors spread; (ii) which aspects of a policy's distorted valuation enhance or impede diffusion; and (iii) which aspects of the network's topology enhance or impede diffusion.

The analytical framework advanced here draws on one of the major findings emerging from empirical and theoretical analyses of how social structure relates to behavior: social-network structure affects how information flows, what access individuals have to various types of information, how policy choices are made and how actions are diffused. Notable examples have been recorded in sociology (e.g., Granovetter 1985; Smelser and Swedberg 2005), economics (see the review in Goyal 2016; Jackson 2016), and politics, public policy, public administration and international relations (see the review in Victor et al. 2018). Likewise, fruitful investigations concerning the effects of social networks on policy outcomes have been published during the last two decades (for a review, see Boucher and Fortin 2016, 280-3; see also Desmarais et al. 2015). 
The analytical framework integrates a variety of policy actors, including policy entrepreneurs - individual or collective actors who seek to bring about policy changes that either alter the status quo in given policy domains (e.g. Kingdon 1984) or block such changes (Ackrill and Kay 2011). Policy entrepreneurs influence information flows by gathering, centralizing, shaping and distorting information, as well as by strategically disseminating that information to policy participants (for a review, see Boasson and Huitema 2017; see also Maor 2017). In addition, a crucial function includes the delivery of information to decision-makers who need guidance in making sense of ambiguous policy problems (e.g., Kingdon 1984). Recently, Arnold et al. (2017) found that "the ability to access and deploy novel, policy-relevant information and resources is particularly important when policy entrepreneurs are seeking to disrupt a policy equilibrium [...]" (p. 433).

The analytical framework follows Baumgartner and Jones's $(2015,15)$ broad definition of information as referring not merely to statistical evidence but also to qualitative information regarding the policy problem, the solution and the policy process itself, as well as to beliefs that motivate professionals and mobilize the public. The analytical framework also accords pride of place to the socio-psychological dimension in information diffusion, the importance of an idea's emotional quality (Cox and Béland 2013) and the derived leverage enjoyed by emotional entrepreneurs (Maor 2017; Maor and Gross 2015). These elements have recently been highlighted in a study concerning polarizing issues in US public-policy debates over gun control, same-sex marriage and climate change. The study demonstrated that the presence of moralemotional words in messages increased their diffusion by a factor of $20 \%$ for each additional word and that moral-emotional language increased diffusion more strongly within liberal and conservative networks and less strongly between the two networks (Brady et al. 2017). Skillful policy entrepreneurs can therefore use social networks to influence flows of distorted policy valuations and, thereby, policy perceptions at the societal and elite levels. Further, introducing emotions into interbubble dynamics highlights the possibility that the source (bubble) and the recipient (bubble) may not be purely coincidental, because policy investment in some policy areas may be more vulnerable to emotion regulation by emotional entrepreneurs.

In the analytical framework, much weight is placed on the spread of human behaviors. When policy response is not directly sensitive to changes in the rate or severity of the policy problem over an extended period of time, attention should be directed toward the behaviors of policy actors and individuals involved in this self-sustaining process (e.g., political participation; policy compliance). Studies have demonstrated that behavior simply does not spread in the way that information does. They also show that different types of networks confer different kinds of benefits and disadvantages. Perhaps most relevant to our study is the differentiation between simple contagions which can be spread by a single contact — such as measles or a tweet (e.g., a new policy belief, fad, or fashion), in a process that often involves minimal effort or cost - and complex contagions which require social reinforcement (e.g., nudges) from multiple neighboring contacts in a social network (Centola and Macy 2007; Centola 2018) in a process that may be costly. Local processes of social reinforcement, which are involved in complex contagions, may also be time-consuming, especially when some individuals require numerous recommendations and others refrain from action until every single person they know — which may amount to tens or hundreds - has acquired the information and acted upon it. Weighing adopters against non-adopters by reputation-sensitive individuals and policy actors may make individuals relatively conservative and less likely to act on the information that they acquired early on (Centola 2018). 
Understanding the puzzling aspect of interbubble dynamics thus requires a more nuanced theoretical approach than the "orthodox" policy-diffusion explanations. We cannot impose the default way of thinking about the transmission of policy ideas — which uses epidemiology as a reference point because of its convenience, while disregarding the role of social reinforcement - especially when we know that human behavior is involved in self-sustaining processes in policy development and that human beings are wary of manipulation on social media and other outlets.

\section{The Analytical Framework}

The premises underlying this conceptual article are that: (i) policymakers' efficiency in matching the intensity of the policy instrument to the intensity of problems over the long-term can only be defined relative to an information set and a timescale, similar to market efficiency (Sohn and Sornette 2017); (ii) dynamic social networks are interconnected rather than isolated, that is, a given social network depends on the dynamic processes that occur in some other social networks; and (iii) the causes of policy problems are "matters of interpretation and social definition" (Cobb and Elder 1983, 172). Given a shared information set, a policy bubble in a certain policy domain or jurisdiction may constitute an information event for another policy bubble that has inflated elsewhere.

An information event in a policy system which shares an information set with another policy system refers to the diffusion of new information through a social context that can potentially change people's sensitivities regarding policy-related aspects at the receiving end. One example is information contagion which spreads fears from one network to another. Another is contagion through interlinked or related public goods and strategies, for instance when some governments are forced either to reduce/stop or begin/accelerate the production of certain public goods, leading to cascades of losses/gains which spread, through exposure, to common factors. Consequently, a policy bubble in a given domain could potentially cause a gradual or, alternatively, a large and sudden inflation or deflation of a policy bubble in the same domain elsewhere (i.e., in another jurisdiction), or in another policy domain in the same jurisdiction or elsewhere. This may be the case particularly when information contains contagious narratives that are largely creative and innovative, or that resonate emotionally, and are therefore easily transmitted from one policy bubble to another.

The framework advanced here incorporates independent variables on two different levels: (1) bubble-bubble (or interbubble) connectivity information as perceived by network members; and (2) the social-network structure. For the former, interbubble connectivity information refers to policy-relevant information transmitted from one bubble to another. This information may reflect either a correct policy valuation or a distorted one and each of these policy valuations may be perceived as either a fact or as an opinion. This focus on perceptions of information is analytically necessary because differentiating between facts, which help us to determine whether something is true or false, and opinion - which reflects the beliefs and values of whoever expresses it - has proved a challenge for large segments of society. A recent survey found that Republicans and Democrats in the US are more likely to think that news statements are factual when they appeal to their side - even if they are opinions (Pew Research Center 2018).

The theoretical framework advanced here focuses on distorted interbubble connectivity information because the direction of change in interbubble dynamics is not obvious, as is likely in the case of correct information which is perceived as fact and is most likely to facilitate bubble termination. Accurate interbubble connectivity information that is perceived by network 
members as an opinion is fully integrated into the analytical framework.

Distorted interbubble connectivity information that is perceived by individuals as fact allows for no (or very little) gap-filling by policy actors and/or by ordinary people. This characteristic has two consequences. First, regarding network hub function, this distorted valuation is likely to be transmitted via simple contagion: hubs are likely to become infected early on because they have many contacts and, once infected, are likely to act as accelerants, simply spreading the "infected" information to everyone they know (Centola and Macy 2007). Second, the behaviors of policy entrepreneurs and other policy actors may remain passive or be understood as exogenous because no gap-filling is required. Furthermore, when distorted information is perceived as a fact, it leaves relatively little leeway for highly connected policy actors to manipulate information in order to shift the opinions and actions of others deliberately. Social networks that are exposed to distorted interbubble connectivity information that is perceived as fact may therefore lack the additional layer of strategic interactions (e.g., Jackson 2008).

In contrast, when distorted interbubble connectivity information is perceived as an opinion, people must interpret the information they receive from others, compare it with other opinions that they encounter and decide with whom to conform. In other words, the perception of distorted interbubble connectivity information as an opinion opens a window for gap-filling by policy actors that aims to provide answers to questions posed by network members, such as: Is the policy instrument used properly?; Is this the right policy instrument? The answers to these questions - one relating to the intensity or scale of use, the other to the type of policy instrument used - may change policy dynamics and, at times, also the dynamic of contagion.

Regarding policy dynamics, changes in the salience assessment of a policy by policymakers, citizens, interest groups and the media may lead to an alteration in the level of mobilization (e.g., because of a change in the inclination to test new ideas) and in the cognitive commitment of citizens, social groups and public officials to the policy at hand. Further, a change in the dominant "image" of the policy instrument can lead to a shift in the venue of decisionmaking and this may bring about an ideational change, undermining the bases of support for the prevailing policy valuation. Such a change will depend, among other factors, on policyimage resilience (Mondou et al. 2014). New interpretations may also divert public attention to what (influential) network members who supported, or chose not to oppose, the policy's initial overproduction consider unanticipated adverse outcomes. They can likewise expand electoral opportunities for politicians, as well as the political coalition for policy change, or undermine those opposing it by producing alternative cost-benefit calculations or by leveraging more popular mechanisms (e.g., market or non-market mechanisms).

Regarding changes in the dynamics of contagion, gap-filling of distorted information that is perceived as an opinion may increase the complexity of the information, thereby increasing the need for reputation-sensitive individuals to seek social enforcement before deciding to adopt and act upon the new information (Centola 2018). Once individuals pay more attention to a behavior's relative prevalence among most or all of their social contacts, weighing adopters against non-adopters, hubs are likely to become "infected" much later on and, once infected, will not be able to act effectively as accelerants. This is because, having spread the "infected" information to everyone they know, those recipients will weigh adopters against non-adopters before deciding to adopt the new information and act upon it.

Distorted interbubble connectivity information which is perceived as an opinion also provides a great deal of leeway for strategic interaction and information manipulation by policy actors, 
in ways that are rapidly changing according to technological developments. Further, those social networks exposed to such opinions may manifest multiple layers of strategic interactions. Highly connected policy entrepreneurs may withhold or distort information that will prove useful in understanding the objective value of the policy instrument. They may also attempt to change how people think about what is true and important, thus exerting a profound impact on the diffusion of information and social learning (Golub and Sadler 2016). They may interact with the media and utilize word of mouth, with important implications for social learning. Likewise, they can increase the likelihood of information awareness and act as amplifiers of supporting or undermining policy overproduction signals.

However, to what extent and in what direction are policy dynamics likely to change? To answer this question, we integrate into our framework the role of network segregation in a social network that occurs "[...] when all the members of one class of persons are cut off from all relationships with all members of other classes" (Freeman 1978, 414). This term grasps agents' tendency to associate with other agents who share similar characteristics, such as race, nationality, gender and cognitive and behavioral characteristics - including personal tastes and the propensity to cooperate with others - as well as genetic traits. One example is separation in geographical space according to a slight ethnic preference in friendships and social interactions (e.g., Schelling 1971).

In segregated networks, social ties tend to be limited within groups of similar people and largely fail to expand to groups that differ in terms of some traits or sets of traits (Moody 2001). This, in turn, inhibits communication and learning across groups (e.g., Centola 2010), causing knowledge and behaviors to become localized in social space (McPherson et al. 2001). This has been increasingly noticeable with the advent of online social networks, particularly related to phenomena such as informational bubbles, opinion polarization and fake news (Lee et al 2014). In addition, segregated networks may witness a relatively low level of tolerance towards members of other groups, inducing an additional level of heterogeneity (e.g., Aits et al 2019).

\section{Hypotheses}

The variations in bubble connectivity information and patterns of social network segregation generate numerous hypotheses, as follows.

H1. Distorted interbubble connectivity information which is perceived by individuals at the receiving end as a fact is likely to lead to a simple contagion process, thereby resulting in a stronger and more sustainable inflated valuation of the policy instrument and, thus, a relatively stable and self-sustaining policy bubble at the receiving end.

Figure 1 provides a graphic representation of the relevant processes depicted here. The premise underlying this hypothesis is that, when distorted interbubble connectivity information is perceived by individuals at the receiving end as a fact, there is no need for gap-filling. They do not need to interpret the information they receive from others or decide whether they intend to adopt and act upon the new information. The source bubble therefore operates as an exogenous factor, facilitating the diffusion of distorted information and limiting the effects of network segregation, if such effects indeed exist.

In addition, the ease of information processing, which is characteristic of this relatively simple and clear type of perceived information, increases contact rates among network members at the receiving end, likewise limiting attempts by highly connected policy entrepreneurs to interfere with the transmission of information that undermines the prevailing policy valuation 
at the receiving end. Furthermore, increased contact rates among network members and the simplicity of perceived information can lead to more individuals joining the network, thereby increasing the number of "infected" members. These processes, combined together, may be likely to lead to a simple contagion process whereby the spread of information is viral in nature and nearly automatic, with minimal effort and cost. This process solidifies the already distorted policy valuation at the receiving end, thereby contributing to bubble sustainment.

Figure 1. Distorted interbubble connectivity information that is perceived as factual in non-segregated social networks (Hypothesis I)

Distorted interbubble connectivity information that is transmitted via non-segregated social networks and is perceived as a fact

- No gap-filling by policy actors and individuals

- Lack of strategic interaction among policy entrepreneurs

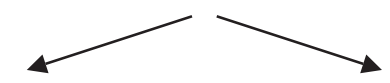

Simple contagion process

- A hub is likely to become "infected" early

- Once the hub is infected, it acts as an accelerant

Increasing contact rate between and amongst policy actors and individuals due to ease of information processing
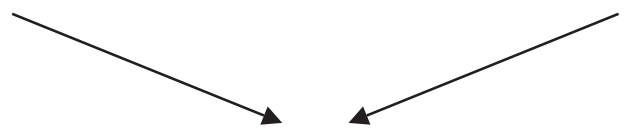

Stronger and more sustainable inflated valuation of the policy instrument at the receiving end

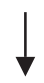

A relatively stable and self-sustaining policy bubble at the receiving end

Source: the Author

Even when distorted interbubble connectivity information that is perceived as a fact is introduced via a new medium and/or at a level of intensity that crosses a tipping-point (e.g., a relatively high visual-emotional degree), the weak ties activated and/or the new ties created among network members do not interfere with the diffusion and social-learning processes. Rather, they create more channels for social/emotional contagion and amplification of the distorted information transmitted from the source bubble.

Distorted information that is perceived as a fact may also help people from similar backgrounds predict others' behavior with more accuracy, as the rationale of the prevailing distorted policy valuation at the receiving end solidifies. Subsequently, this introduces another common dimension shared by supporters of the overproduction of the policy at hand and reduces the potential for loss of confidence and for coordination failure, which occur when people are unsure of others' actions or beliefs.

H2. In non-segregated or less-segregated social networks, distorted interbubble-connectivity information which is perceived as an opinion is likely to lead to highly complex types of diffusion processes, the net impact of which can be either corrective or distortive insofar as the prevailing policy valuation at the receiving end is concerned. 
Figure 2 offers a graphic representation of the relevant processes depicted here. The network topology and the type of perceived information can influence information diffusion by modifying contact rates, the dynamics of contagions and the diversity of policy valuations. When policy entrepreneurs fill the gaps in distorted interbubble-connectivity information that is perceived as an opinion, this increases the complexity of interbubble connectivity information. This, in turn, may have two consequences. First, growing information complexity may decrease contact rates among network members as a result of increased difficulty in information processing. This may inhibit information diffusion, leaving peoples' opinions intact and, consequently, sustaining the prevailing policy valuation. Second, growing information complexity may increase the need of reputation-sensitive individuals to seek social enforcement before deciding to adopt and act upon the new information (Centola 2018). Consequently, rather than spreading like viruses, hubs are likely to become "infected" much later (relative to cases involving simple information). Once infected, they will not be able to act effectively as accelerants because, having spread the "infected" information to everyone they know, these recipients will also weigh adopters against non-adopters. This, in turn, may stymie the spread of behaviors that play a role in the sustainment of the policy bubble at hand.

Figure 2. Distorted interbubble connectivity information that is perceived as an opinion in non-segregated and less-segregated social networks (Hypothesis II)

Distorted interbubble connectivity information that is transmitted via non-segregated and less segregated social networks and is perceived as an opinion

- Gap-filling by policy entrepreneurs

- Multiple layers of strategic interactionamong policy actors

Growing complexity of information

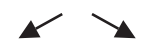

Decreasing contact rates among network members

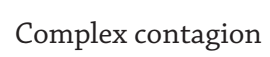

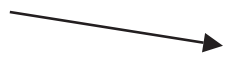

Increase in the diversity of policy valuations

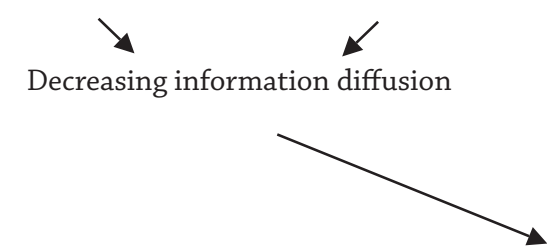

Corrective or distortive net impact for the prevailing policy valuation at the receiving end

Increasing information diffusion

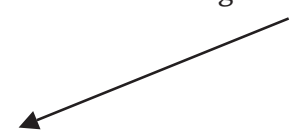

The "dilution effect"

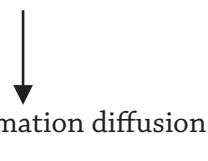

Bubble sustainment (for distortive net impact) or termination (for corrective net impact)

However, such gap-filling of distorted interbubble connectivity information that is perceived as an opinion may also trigger a process with a contradictory outcome. In non-segregated or less-segregated networks, gap-filling of such information may increase the diversity of policy valuations, thereby "diluting" the prevailing policy valuation by allowing the correct policy valuation, or competing distorted valuations, to invade social networks successfully. For example, a correct policy valuation, or competing distorted valuations perceived as an opinion, may trigger controversy within the professional community. Senior civil servants, themselves 
policy entrepreneurs who are attuned to controversy in the professional community, may act to correct the prevailing policy valuation, or deflate the policy bubble unilaterally, rather than rubber-stamping inflated levels of policy production. By the same token, correct interbubble connectivity information that is perceived as expert opinion may decrease the number of distorted hosts. This, in turn, may signal to network members that correction of policy valuation is in order, thereby deflating the policy bubble.

In addition, certain interpretations of interbubble connectivity information that is perceived as an opinion can cause a negative change in peoples' perceptions regarding the worthiness of given policy-related actors or institutions and this, in turn, can have a knock-on effect on the worthiness of other actors, thus creating a form of information contagion that undermines the prevailing policy valuation. High policy-valuation richness can therefore reduce the risk of "infection" via the "dilution effect". Increasing diversity in policy valuations might therefore increase information diffusion, the impact of which may undermine the prevailing policy valuation. This may be a very slow process because "a new story correcting a false story may not be as contagious as the false story, which means that the false narrative may have a major impact on [...] activity long after it is corrected" (Shiller 2019, 97).

The net impact of decreasing information diffusion as a result of decreasing contact rates and the change in the dynamic of contagions caused by the growing complexity of new information, on the one hand, and increasing information diffusion due to increasing diversity of policy valuations, on the other hand, can be either corrective or distortive insofar as the prevailing policy valuation at the receiving end is concerned. It depends on the relative importance of the former process versus that of the latter.

H3. In segregated social networks within policy domains, distorted interbubble information that is perceived as an opinion is likely to lead to strategic diffusion accompanied by decreasing contact rates among network members, thereby resulting in a stronger and more sustainable inflated valuation of the policy instrument at the receiving end and, thus, a relatively stable or growing policy bubble at the receiving end.

Figure 3 provides a graphic representation of the relevant processes depicted here. In such contexts, policy actors can limit the expansion of imaginable, workable and plausible policy alternatives within particular social groups in the following ways. First, they can take advantage of the multiple layers of strategic interactions by incorporating social network information in the design of influence strategies in a way that reduces waste of resources (e.g., targeting/ campaigning costs) and generates greater impact. This can be undertaken by strategic diffusion, that is by increasing or decreasing the optimal influence strategy (i.e., targeting individuals with low or high connections) depending on the content of the interaction (Galeotti and Goyal 2009; see also Galeotti et al. 2013; Bloch et al. 2018; and Chatterjee and Dutta 2016; see also Galeotti and Goyal 2009). 
Figure 3. Distorted interbubble connectivity information that is perceived as an opinion in segregated social networks (Hypothesis III)

Distorted interbubble connectivity information that is transmitted via segregated social networks and is perceived as an opinion

Segregated social networks

- Gap-filling by policy entrepreneurs

- Multiple layers of strategic interactionamong policy actors

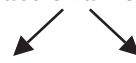

Growing complexity of information

Policy actors inhibit the spread of certain policy valuations

via strategic diffusion

Decreasing contact rates Complex contagion among network members witin groups across groups

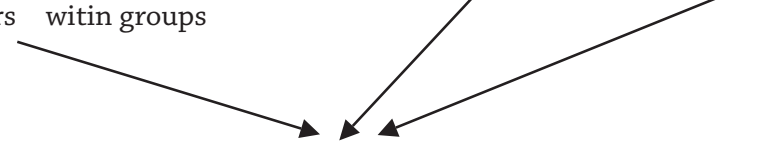

Decreasing information diffusion

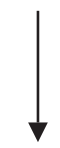

Poor learning and communication across groups

A relative stable inflated valuation of the policy instrument at the receiving end

A relative stable and self-sustaining policy bubble at the receiving end

\section{Source: The Author}

Second, policy entrepreneurs and other policy actors can take advantage of the fact that information can pass relatively slowly to inhibit the spread of certain interpretations deriving from competing opinions. Slow transmission of information may be caused by the growing complexity of information - the derived consequences of which may be decreasing contact rates among network members across social groups and complex contagion within groups - as well as by the poor learning and communication across social groups that characterizes segregated social networks. Slow transmission of information allows policy actors more time to counterframe the status quo as the safer option, distort scientific facts, regulate populations who are at risk of becoming "corrected" (e.g., concerning closure in small social networks, see Coleman 1988) and interfere with the transmission of particular policy valuation. Overall, these processes support the inflated valuation of the policy instrument at the receiving end, leading to a relatively stable policy bubble at the receiving end.

When investigating the aforementioned processes, it is important to distinguish between the level of social network connectivity and the segregation patterns within a policy system, on the one hand, and the level of connectivity and segregation patterns among elite decisionmakers on the other. Both may be of vast significance in amplifying or dissipating information shocks to the system; yet, at the same time, such shocks can be triggered at one level. Gauging the net effect requires recognition of the conditions under which opinions will spread across the entire interacting network system, as compared with a spread to only one type of network (e.g., a social or elite network), with minimal isolated "distortions" on other network types. It also requires consideration of a situation wherein two or more pieces of distorted interbubble connectivity information, which are perceived as opinions, spread within the same social network or within different networks and interact dynamically with one another. Depending 
on the characteristics of social-network structure, network type can have either a profound or a minor effect on the spread of information from one policy bubble to another. Identifying the conditions in which these cases occur is vital to our understanding of interbubble dynamics. Needless to say, the effects of these patterns may vary according to policy contexts.

To sum up, a careful examination of network interaction patterns should help us disentangle information originating in one policy domain (e.g., wherein the target bubble originally developed) from that which is the product of another policy bubble (i.e., the source bubble) - both fuel the target bubble, together or separately. It also allows us to gauge deliberate choices made by policy entrepreneurs and other policy actors, operating within social network contexts, when spreading different types of information, and also their policy implications. Needless to say, the behavior of highly skilled policy entrepreneurs/actors operating in a network may affect not only policy investment and production but also the evolution of the network and the resulting transmission of shocks and crises (e.g., Jackson 2016, 75). We now turn our attention to the relevant methodological toolbox.

\section{Methodology}

Before discussing the methodology, let us first articulate more accurately the relevant network characteristics necessary for empirical measurement. The actors in the theoretical framework are individuals. However, it is not impossible to have multi-modal networks, such as two modes — individuals and policy-relevant organizations — wherein individuals can also belong to organizations. Network mapping will reveal the level of influence wielded by policy entrepreneurs, or "hubs," which depends in part on the level of inter-nodal connections in his or her area of activity. This connectivity may be captured using Bonacich's power centrality. More power means that a policy entrepreneur has a larger number of connections to less-connected nodes, while less power means that he or she has a larger number of connections to more wellconnected nodes.

Regarding the boundaries of the network, the policy actors in the framework advanced here are bounded by specific policy bubbles. The social tie used in the framework is information sharing (e.g., Facebook friends), but the information is not necessarily related to the policy bubbles. The criteria for segregation are the same as for the relational ties, namely information sharing. Measuring diffusion of information may rely on behaviors that can be obtained from metadata, or inferred from messages. Measuring the impact of this diffusion can rely on policy-investment decisions in real and controlled settings. Identifying causal associations between social networks and outcomes of interest presents empirical challenges. These concerns may be addressed by pursuing multiple research strategies. I elaborate three options: big data analysis, agent-based modeling and experimentation.

Analyzing the information spreading patterns in multiple social networks can take advantage of the modern advances in data science. Important in this regard are the models developed so far to analyze the adaptive process in information diffusion, which are used to characterize the dynamic of opinion formation, such as models concerning social segregation (Gross and Blasius, 2008; Nardini et al. 2008). Complex network structures can be uncovered by analyzing the online social networks that constitute the most important information spreading platforms. Complex patterns of information-spreading can likewise be gauged by analyzing instant messengers, Twitter, blogs and Facebook, as well as other networks that embed the rich information spreading phenomenon, such as Instagram, Flickr, YouTube and so on. It is possible to analyze information spreading by focusing on information broadcasting, information sharing 
and so on.

Opinions also compete on social networks. Different opinions are distributed in the networks and interact with one another. This calls for the use of agent-based models (ABM) for understanding opinion competition dynamics and competitive diffusion processes on multiplex networks, where the networks are made up of different layers that comprise the same nodes and a given type of edges in each layer. As a hypothesis-generating method, ABM is an efficient way to examine theoretical explanations formally, to construct new expectations and gauge potentially surprising findings, to concretize theoretical puzzles by transforming hypotheses to mechanisms and to enrich networked experiments. There is abundant research on opinion dynamics over multiplex networks wherein agents interact with bounded confidence. A number of scholars have provided comprehensive surveys of this stream (Lorenz 2007; Castellano et al. 2009; see also Myers and Leskovec 2012; Antonopoulos and Shang 2018). This method may be relevant for understanding social contagion processes during which individuals who hold opinions regarding a policy instrument exchange views and compromise, if their opinions do not differ by more than a given threshold. It can also infuse meaning to empirical analysis of deductive- and ABM-derived expectations of interbubble dynamics by using massive date sets which represent large-scale social systems.

Networked experiments provide another possible methodology that can help us to explore the implications of interdependencies for policy investment and production. Social settings may be randomized and engineered to enable exploration of the outcomes of social interaction and the unpacking of nuanced behavioral mechanisms that explain social effects. The ability to test complex dynamic hypotheses concerning social behavior has radically increased with the growth of digital tools such as Facebook applications and Amazon Mechanical Turk, as well as increasing collaboration with platform developers and website administrators (for a review, see Aral 2016). Notable examples include digital experiments concerning information sharing and diffusion (Bakshy et al. 2012). The design of networked experiments (i.e., setting, sampling, randomization and treatment assignment), as well as the analysis of such experiments, are discussed elsewhere (Aral 2016). Lab experiments manipulating policy bubbles provide a further avenue for testing the analytical framework advanced here (for a review of lab experiments in information flows through varying network structures, see Choi et al. 2016, 465-7). Lab experiments could be used, for example, to gauge the extent to which factual information is transformed into opinions as it is transmitted through the network (e.g., whether an individual believes "official statistics" depends on the source from which he/she hears them). Researchers can also gauge causal estimations of network effects by implementing exogenous network structures in the lab (Choi et al. 2016).

Regarding the identification of interbubble dynamics and the measurement of policy bubbles, the focus should be placed on the shared information set, as well as on the direct indicators of the policy problem and on government investment in a policy instrument in order to gauge the degree of overinvestment in a policy tool relative to the severity of the policy problem. In addition, changes in the macropolitical agenda might be gauged by measuring fluctuations in the extent of media coverage because media attention plays a key role in processes of social and emotional contagion and, subsequently, links fluctuations in media attention to the life-cycle of a policy bubble.

A potential shared information set is, for example, the basic emotion of disgust (Kam and Estes 2016). Scholars may draw on recent findings regarding how individual differences in disgust 
sensitivity (Inbar, Pizarro, and Bloom 2009; see also Inbar et al. 2012; Terrizzi et al. 2010) inform demand for policies in different domains that are designed to protect citizens from physical, moral and imaginary contamination (Kam and Estes 2016). They may therefore examine the existence of potential interbubble dynamics in the policy domains of food protection, water pollution, immigration, abortion, gay marriage, stem-cell research, euthanasia and medical marijuana. These policy areas are of interest because: (i) they are independent from economic bubbles and therefore are not the consequences of economic bubbles and thus they can develop under a variety of circumstances; (ii) they are characterized by strong indicators of the severity of the policy problem; and (iii) they are distinct and very different policy areas in substantive terms, thereby increasing the potential of generalization, should common patterns of interbubble dynamics emerge across policy sectors. Utilizing the aforementioned research strategies may highlight patterns and provide confirmation or disconfirmation of the assumptions and hypotheses advanced here.

\section{Conclusions}

Over the past few years, political scientists established the plausibility of policy bubbles, principally claiming that such bubbles are fueled by self-reinforcing processes and contagion, yet ignoring the possible impact of interdependence between complex policy systems on the sustainment of policy bubbles. To improve our understanding of such a complex phenomenon, this article utilizes robust findings in the study of how information and behavior spread in the social sphere to develop an analytical framework in which one policy bubble is viewed as a site for producing information that may fuel another. Regardless of the dynamics at play, the mere act of locating information sets that are shared among policy bubbles across policy sectors, levels of government, states and other jurisdictions brings the problem of bubble sustainment into sharper focus than ever before. It can assist efforts to identify policy bubbles and potentially contribute to the debate concerning how to respond to suspected policy bubbles.

Considering that diffusion processes "tie in very closely to the basic architecture of a population's network" (Jackson et al. 2017, 66), the article develops a social network perspective on interbubble dynamics. A social network perspective provides powerful tools for analyzing information diffusion processes, as well as the extent of contagion which depends to a great extent on network structure. It captures the potential effects of large-scale network structure on aggregate behaviors and outcomes, in addition directing attention to variations between societies with regard to the sustainment of policy bubbles (e.g., fragmented societies may exhibit more fragmented networks). Further, such a perspective allows us to develop conceptual insights of a realistic nature. One reason for this lies in the network concept that "does not imply equilibrium orientation, and involves much lower integration" (Schneider and Bauer 2016, 74). Another relates to the fact that, even when people are not familiar with the details of networks, they instinctively impart information to others who share their demographics. As complicated objects, the article considers it useful to simplify networks by focusing on one property, namely network segregation. This conceptual strategy enables demonstration of the potential importance of network segregation in transmitting interbubble connectivity information.

Taken together, the added value of a social network perspective on interbubble dynamics can potentially explain empirical regularities manifesting in policy bubble processes. Specifically, by applying a multi-network logic and imposing multiple policy domains on bubbly policy processes, a social network perspective can widen the number of mechanisms that may exist for policy bubble sustainment. An empirical examination guided by this perspective can reveal the 
role played by interbubble dynamics (or the lack thereof) alongside self-reinforcing processes and contagion. This is the article's main contribution.

\section{Bibliography}

Abrajano, M., \& Hajnal, Z. L. (2015). White Backlash: Immigration, Race, and American Politics. Princeton, NJ: Princeton University Press.

Andreas, P. (2000). Border Games: Policing the U.S.-Mexico divide. Ithaca, NY: Cornell University Press.

Ackrill, R. \& Kay, A. (2011). Multiple Streams in EU Policy-Making: The Case of the 2005 Sugar Reform. Journal of European Public Policy, 18, 72-89.

Aits, D., Carver, A., \& Turrini, P. (2019). Group Segregation in Social Networks. In N. Agmon, M.E Taylor, E. Elkind \& M. Veloso (Eds.), Proceedings of the $18^{\text {th }}$ International Conference on Autonomous Agents and Multiagent Systems. May 13-17, 2019 (pp. 1524-1532). Montreal, Canada: International Foundation for Autonomous Agents and Multiagent Systems.

Antonopoulos, C. G. \& Shang, Y. (2018). Opinion Formation in Multiplex Networks with General Initial Distribution. Scientific Reports - Nature, 8, 2852-2864.

Aral, S. (2016). Networked Experiments. In Y. Bramoullé, A. Galeotti \& B.W Rogers (Eds.), The Oxford Handbook of the Economics of Networks (pp. 376-411). Oxford and New York: Oxford University Press.

Arnold, G, Nguyen Long, L. A. \& Gottlieb, M. (2017). Social Networks and Policy Entrepreneurship: How Relationships Shape Municipal Decision Making about High-Volume Hydraulic Fracturing. Policy Studies Journal, 45(3), 414-441.

Bakshy, E., Rosenn, I., Marlow, C., \& Adamic, L. (2012). The Role of Social Networks in Information Diffusion. Proceedings of $21^{\text {st }}$ International Conference on World Wide Web, 519-528. ACM, New York.

Baumgartner, F. R. (2015). Party Competition and Friction. Paper presented at the workshop on The Politics of Non-Proportionate Policy Response, ECPR Joint Workshops, Warsaw, Poland, March.

Baumgartner, F. R. \& Jones, B. D. (1993). Agendas and Instability in American Politics. Chicago, IL: University of Chicago Press.

Baumgartner, F. R. \& Jones, B. D. (2015). The Politics of Information: Problem Definition and the Course of Public Policy in America. Chicago, IL: University of Chicago Press.

Behn, D., Fauchald, O., \& Langford, M. (2015). Bursting Policy Bubbles: The International Investment Treaty Regime. PluriCourts Research Paper, (15-15).

Bennett, C. J. (1991). What Is Policy Convergence and What Causes It? British Journal of Political Science, 21(2), 215-233.

Bennett, C. J. \& Howlett, M. (1992). The Lessons of Learning: Reconciling Theories of Policy Learning and Policy Change. Policy Sciences, 25, 275-294.

Berry, F. S. \& Berry, W. D. (1990). State Lottery Adoptions as Policy Innovation: An Event History Analysis. American Political Science Review, 84(2), 395-415.

Berry, F. S. \& Berry, W. D. (1999). Innovation and Diffusion Models in Policy Research. In P.A Sabatier (Ed.), Theories of the Policy Process (pp. 169-199). Boulder, CO: Westview. 
Berry, F. S., \& Berry, W. D. (2018). Innovation and Diffusion Models in Policy Research. In C.M Weible \& P.A Sabatier (Eds.), Theories of the Policy Process (pp. 253-300). New York, NY: Westview Press.

Bloch, F., Demange, G. \& Kranton, R. (2018). Rumors and Social Networks. International Economic Review, 59(2), 421-448.

Boasson, E. L. \& Huitema, D. (2017). Climate Governance Entrepreneurship: Emerging Findings and a New Research Agenda. Environment and Planning, C: Politics and Space 35(8), 1343-1361.

Bonacich, P. (1987). Power and Centrality. American Journal of Sociology, 1, 1170-1182.

Boushey, G. (2010). Policy Diffusion Dynamics in America. New York, NY: Cambridge University Press.

Boushey, G. (2016). Targeted for Diffusion? How the Use and Acceptance of Stereotypes Shape the Diffusion of Criminal Justice Policy Innovations in the American States. American Political Science Review, 110(1), 198-214.

Brady, W. J., Wills, J. A., Jost, J. T., Tucker, J. A., \& Van Bavel, J. J. (2017). Emotion Shapes the Diffusion of Moralized Content in Social Networks. Proceedings of the National Academy of Sciences of the United States of America, 114, 7313-7318.

Bramoullé, Y., Galeotti, A., \& Rogers, B. W. (Eds.) (2016). The Oxford Handbook of the Economics of Networks. Oxford and New York: Oxford University Press.

Braun, D. \& Gilardi, F. (2006). Taking ‘Galton's Problem' Seriously: Towards a Theory of Policy Diffusion. Journal of Theoretical Politics, 18(3), 298-322.

Boucher, V. \& Fortin, B. (2016). Some Challenges in the Empirics of the Effects of Networks. In Y. Bramoullé, A. Galeotti \& B.W Rogers (Eds.), The Oxford Handbook of the Economics of Networks (pp. 277-302). Oxford and New York: Oxford University Press.

Castellano, C., Fortunato, S., \& Loreto, V. (2009). Statistical Physics of Social Dynamics. Reviews of Modern Physics, 81, 591-646.

Centola, D. (2010). The Spread of Behavior in an Online Social Network Experiment. Science, 329(5996), 1194-1197.

Centola, D. (2018). How Behavior Spreads: The Science of Complex Contagions. Princeton, NJ: Princeton University Press.

Centola, D. \& Macy, M. (2007). Complex Contagions and the Weakness of Long Ties. American Journal of Sociology, 113(3), 702-734.

Chatterjee, K. \& Dutta, B. (2016). Credibility and Strategic Learning in Networks. International Economic Review, 57(3), 759-786.

Chavez, L. R. (2008). The Latino Threat: Constructing Immigrants, Citizens, and the Nation. Palo Alto, CA.: Stanford University Press.

Choi, S., Gallo, E., \& Kariv, S. (2016). Networks in the Laboratory. In Y. Bramoullé, A. Galeotti \& B.W Rogers (Eds.), The Oxford Handbook of the Economics of Networks (pp. 440-478). Oxford and New York: Oxford University Press.

Cobb, R. W. \& Elder, C. D. (1983). Participation in American Politics. Baltimore, MD: John Hopkins University Press.

Coleman, J. S. (1988). Social Capital in the Creation of Human Capital. American Journal of Sociology, 94 (Supplement), S95-120. 
Cox, R. H. \& Béland, D. (2013). Valence, Policy Ideas and the Rise of Sustainability. Governance, 26(2), 307-28.

Desmarais, B. A., Harden, J. J., \& Boehmke, F. J. (2015). Persistent Policy Pathways: Inferring Diffusion Networks in the American States. American Political Science Review, 109(2), 392-406.

DiMaggio, P. J. \& Powell, W. W. (1983). The Iron Cage Revisited: Institutional Isomorphism and Collective Rationality in Organizational Fields. American Sociological Review, 48(2), 147-160.

Dolowitz, D. P. \& Marsh, D. (1996). Who Learns What from Whom: A Review of the Policy Transfer Literature. Political Studies, 44(2), 343-357.

Freeman, L. C. (1978). Segregation in Social Networks. Sociological Methods \& Research, 6(4), 411429.

Galeotti, A. \& Goyal, S. (2009). Influencing the Influencers: A Theory of Strategic Diffusion. The Rand Journal of Economics, 40(3), 509-532.

Galeotti, A., Ghiglino, C., \& Squintani, F. (2013). Strategic Information Transmission Networks. Journal of Economic Theory, 148(5), 1751-1769.

Gilardi, F. (2010). Who Learns from What in Policy Diffusion Processes? American Journal of Political Science, 54, 650-66.

Gilardi, F. (2016). Four Ways We Can Improve Policy Diffusion Research. State Politics \& Policy Quarterly, 16(1), 8-21.

Gilardi, F., Shipan, C. R., \& Wueest, B. (2017). Policy Diffusion: The Issue-Definition Stage. Working Paper. Available online at https://www.fabriziogilardi.org/resources/ papers/policy-diffusion-issuedefinition.pdf

Gillard, R. \& Lock, K. (2017). Blowing Policy Bubbles: Rethinking Emissions Targets and Low-Carbon Energy Policies in the U.K. Journal of Environmental Policy \& Planning, 19(6), 638-653.

Golub, B. \& Sadler, E. (2016). Learning in Social Networks. In Y. Bramoullé, A. Galeotti \& B.W Rogers (Eds.), The Oxford Handbook of the Economics of Networks (pp. 504-542). Oxford and New York: Oxford University Press.

Goyal, S. (2016). Networks in Economics: A Perspective on the Literature. In Y. Bramoullé, A. Galeotti \& B.W Rogers (Eds.), The Oxford Handbook of the Economics of Networks (pp. 47-70). Oxford and New York: Oxford University Press.

Graham, E. R., Shipan, C. R., \& Volden, C. (2013). The Diffusion of Policy Diffusion Research in Political Science. British Journal of Political Science, 43(3), 673-701.

Granovetter, M. (1985). Economic Action and Social Structure: The Problem of Embeddedness. American Journal of Sociology, 3, 481-510.

Gross, T. \& Blasius, B. (2008). Adaptive Coevolutionary Networks: A Review. Journal of the Royal Society -- Interface, 5(20), 259-271.

Hall, P. (1993). Policy Paradigms, Social Learning and the State: The Case of Economic Policy-Making in Britain. Comparative Politics, 25, 275-296.

Henry, A. D. (2018). Network Segregation and Policy Learning. In J.N Victor, A.H Montgomery \& M. Lubell (Eds.), The Oxford Handbook of Political Networks (pp. 559-588). Oxford and New York: Oxford University Press.

Inbar, Y., Pizarro, D. A. \& Bloom, P. (2009). Conservatives Are More Easily Disgusted Than Liberals. Cognition and Emotion, 23, 714-25. 
Inbar, Y., Pizarro, D. A., Iyer, R., \& Haidt, J. (2012). Disgust Sensitivity, Political Conservatism, and Voting. Social Psychological and Personality Science, 3, 537-44.

Irvine, J., Miles, I., \& Evans, J. (1979). Demystifying Social Statistics. London: Pluto Press.

Jackson, M. (2008). Social and Economic Networks. Princeton and Oxford: Princeton University Press.

Jackson, M. O. (2016). The Past and Future of Network Analysis in Economics. In Y. Bramoullé, A.Galeotti \& B.W Rogers (Eds.), The Oxford Handbook of the Economics of Networks (pp. 71-82). Oxford and New York: Oxford University Press.

Jackson, M. O., Rogers, B. W., \& Zenou, Y. (2017). The Economic Consequences of Social-Network Structure. Journal of Economic Literature, 55(1), 49-95.

Jasanoff, S. S. (1987). Contested Boundaries in Policy-Relevant Science. Social Studies of Science, 17(2), 195-230.

Jones, B. D., Thomas III, H. F., \& Wolfe, M. (2014). Policy Bubbles. Policy Studies Journal, 42(1), 146-171.

Hood, C., \& Dixon, R. (2015). A Government that Worked Better and Cost Less? Oxford: Oxford University.

Kam, C. D., \& Estes, B. A. (2016). Disgust Sensitivity and Public Demand for Protection. Journal of Politics, 78, 481- 96.

Karch A., Nicholson-Crotty, S. C., Woods, N. D. \& Bowman, A. O. (2016). Policy Diffusion and the Pro-Innovation Bias. Political Research Quarterly, 69(1), 83-95.

Kingdon, J. W. (1984). Agendas, Alternatives, and Public Policies. Boston, MA: Little, Brown.

Lee, J. K., Choi, J., Kim, C., \& Kim, Y. (2014). Social Media, Network Heterogeneity, and Opinion Polarization. Journal of communication, 64(4), 702-722.

Lorenz, J. (2007). Continuous Opinion Dynamics under Bounded Confidence: A Survey. International Journal of Modern Physics C, 18(12), 1819-1838.

Maor, M. (2012). Policy Overreaction. Journal of Public Policy, 32, 231-259.

Maor, M. (2014). Policy Bubbles: Policy Overreaction and Positive Feedback. Governance, 27(3), 469-487.

Maor, M. (2016). Emotion-Driven Negative Policy Bubbles. Policy Sciences, 49(2), 191-210.

Maor, M. (2017). Policy Entrepreneurs in Policy Valuation Processes: The Case of the Coalition for Environmentally Responsible Economies. Environment and Planning C: Government and Policy, 35(8), 1401-1417.

Maor, M. (2019). Overreaction and Bubbles in Politics and Policy." In: A. Mintz \& L. Terris (Eds.), Oxford Handbook on Behavioral Political Science. Oxford Handbooks Online. Oxford: Oxford University Press.

Maor, M. \& Gross, J. (2015). Emotion Regulation by Emotional Entrepreneurs: Implications for Political Science and International Relations. Paper presented at the 73rd Annual Conference of the Midwest Political Science Association, 16-19 April, Chicago.

Martin, A., Moral-Benito, E., \& Schmitz, T. (2019). The Financial Transmission of Housing Bubbles: Evidence from Spain. ECB Working Paper Series No 2245. Frankfurt: European Central Bank.

Martinez-Brawley, E. E. \& Zorita, P.M.-B. (2018). Will We Build a Wall: Fear of Mexican/Latino Immigration in U.S. History. Journal of Sociology \& Social Welfare, 45(2), 157-178. 
Massey, D. S. \& Pren, K. A. (2012). Origins of the New Latino Underclass. Race and Social Problems, 4, 5-17.

McPherson, M., Smith-Lovin, L., \& Cook, J.M. (2001). Birds of a Feather: Homophily in Social Networks. Annual Review Sociology, 27, 415-444.

Meseguer, C. (2006). Rational Learning and Bounded Learning in the Diffusion of Policy Innovations. Rationality and Society, 18, 35-66.

Mondou, M., Skogstad, G., \& Houle, D. (2014). Policy Image Resilience, Multi-dimensionality, and Policy Image Management: A Study of Biofuel Policy. Journal of Public Policy, 34(1), 155-180.

Moody, J. (2001). Race, School Integration, and Friendship Segregation in America. American Journal of Sociology, 107(3), 679-716.

Myers, S. A. \& Leskovec, J. (2012). Clash of the Contagions: Cooperation and Competition in Information Diffusion. IEEE 12th Int. Conf. on Data Mining (ICDM), pp. 539-548.

Nardini, C., Kozma, B., \& Barrat, A. (2008). Who's Talking First? Consensus or Lack Thereof in Coevolving Opinion Formation Models. Physical Review Letters, 100 (15), 158701-158705.

Nicholson-Crotty, S., Peterson, D. A. M., \& Ramirez, M. D. (2009). Dynamic Representation(s): Federal Criminal Justice Policy and an Alternative Dimension of Public Mood. Political Behavior, 31(4), 629-55.

Nisbet, M. C. \& Mooney, C. (2007). Framing Science. Science, 316(6), 56.

Oreskes, N. \& Conway, E. M. (2010). Merchants of Doubt. New York, NY: Bloomsbury Press.

Ostrom, E. (2005). Understanding Institutional Diversity. Princeton, NJ: Princeton University Press.

Pacheco, J. (2012). The Social Contagion Model: Exploring the Role of Public Opinion on the Diffusion of Antismoking Legislation across the American States. Journal of Politics, 74(1), 187-202.

Pew Research Center (June, 2018) Distinguishing Between Factual and Opinion Statements in the News. Retrieved from

https://www.journalism.org/2018/06/18/distinguishing-between-factual-and-opinion-statements-in-the-news/

Pielke Jr., R. (2007). The Honest Broker: Making Sense of Science in Policy and Politics. Cambridge: Cambridge University Press.

Radaelli, C. (2000). Policy Transfer in the European Union: Institutional Isomorphism as a Source of Legitimacy. Governance, 13(1), 25-43.

Robertson, D. B. (1991). Political Conflict and Lesson-Drawing. Journal of Public Policy, 11(1), 55-78.

Robertson, D. B. \& Waltman, J. L. (1993). The Politics of Policy Borrowing. In D. Finegold, L. McFarland \& W. Richardson (Eds.), Something Borrowed, Something Learned? (pp. 21-44). Washington, DC: Brookings Institution Press.

Rose, R. (1991). What Is Lesson-Drawing? Journal of Public Policy, 11(1), 3-30.

Sabatier, P. \& Jenkins-Smith, H. (1993). Policy Change and Learning. Boulder, CO: Westview Press.

Schelling, T. C. (1971). Dynamic Models of Segregation. Journal of Mathematical Sociology, 1(2), 143-86.

Schneider, V. \& Bauer, J. M. (2016). A Network Science Approach to the Internet. In J.M Bauer \& M. Latzer (Eds.), Handbook on the Economics of the Internet (pp. 72-90). Cheltenham: Edward Elgar. 
Schneider, A. L. \& Ingram, H. (1988). Systematically Pinching Ideas: A Comparative Approach to Policy Design. Journal of Public Policy, 8(1), 61-80.

Schneider, A. L. \& Ingram, H. (1993). The Social Construction of Target Populations: Implications for Politics and Policy. American Political Science Review, 87(2), 334-47.

Seljan, E. C. \& Weller, N. (2011). Diffusion in Direct Democracy: The Effect of Political Information on Proposals for Tax and Expenditure Limits in the U.S. States. State Politics \& Policy Quarterly, 11(3), 348-368.

Shiller, R. J. (2019). Narrative Economics: How Stories Go Viral \& Drive Major Economic Events. Princeton, NJ: Princeton University Press.

Shipan, C. \& Volden, C. (2008). The Mechanisms of Policy Diffusion. American Journal of Political Science, 52, 840-857.

Smelser, N. J. \& Swedberg, R. (2005). The Handbook of Economic Sociology. 2nd edition, New York, NY: Russell Sage Foundation.

Sohn, H-U. \& Sornette, D. (2017). Bubbles as violations of efficient time-scales. Institute for New Economic Thinking Working Paper Series, (65). Available online at https://ssrn.com/abstract=3081563.

Terrizzi, J. A., Jr., Shook, N. J., \& Ventis, W. L. (2010). Disgust: A Predictor of Social Conservatism and Prejudicial Attitudes toward Homosexuals. Personality and Individual Differences, 49, 587-92.

Victor, J. N., Montgomery, A. H., \& Lubell, M. (2018). The Oxford Handbook of Political Networks. Oxford and New York: Oxford University Press.

Walker, J. L. (1969). The Diffusion of Innovations among the States. American Political Science Review, 63, 880-99.

Ybarra, V. D., Sanchez, L. M., \& Sanchez, G. R. (2016). Anti-Immigrant Anxieties in State Policy: The Great Recession and Punitive Immigration Policy in the American States, 2005-2012. State Politics and Policy Quarterly, 6(3), 313-39. 